Book reviews

\section{Compliance with Therapeutic Regimens}

Edited by David L Sackett and $R$ Bryan Haynes (Pp xiv \& 293; £I2)

The Johns Hopkins University Press, Baltimore and London, 1976.

This book developed from the proceedings of a workshop/symposium on Compliance with Therapeutic Regimens, held at the McMaster University Medical Centre, Hamilton, Ontario, Canada, in May 1974. It is concerned with 'the extent to which the patient's behaviour (in terms of taking medications, following diets or executing other lifestyle changes) coincides with the clinical prescription'. As such this is a very important book. However, its value is somewhat marred by the deficiencies which often accompany the publishing of proceedings, in particular the very variable quality of the chapters. It could have benefited greatly from more ruthless editing.

Overall, the book is very well organized into sections covering 'The magnitude, determinants and measurement of compliance' (four chapters), 'Strategies for improving compliance' (seven chapters), 'Compliance and therapeutic trials' (two chapters), one chapter on 'Recommendations for future research' and two very extensive appendices. The chapters contain useful, neat summaries at key points, and end with detailed conclusions normally pinpointing areas of ignorance. The four chapters in the first section are particularly useful, especially the tables presenting the key features of numerous studies examining the influence of a wide range of variables on compliance.

Some very interesting conclusions emerge from these literature surveys : for example, only one half of patients on long-term medication are compliant; side effects, severity of illness, and the patient's intellectual level and knowledge of his disease, do not have clear-cut unequivocal effects on compliance. However, the complexity of the medication regimen, the patient's satisfaction with the doctor and family influences have a marked effect on compliance levels; and the picture is complicated by the fact that compliance levels can vary according to how one manages to measure compliance.

The quality of the papers in the second section (on 'Strategies for improving compliance') is very variable. The overall review by Haynes and the final chapter on the role of the pharmacist are excellent, but the chapters on 'Patient education' and on 'Behavioural therapeutics' are poor by comparison. The latter chapter is particularly disappointing in that it fails to highlight the great potential value of a behavioural approach and omits any reference to some very important work, eg, that of Sand, Fordyce and Fowler $^{1}$ on training spinal-cord injured patients to increase fluid intake and output. Instead, it concentrates on conditioned aversion studies which are at best of incidental interest. The other chapters on the 'Influence of the medication' and 'Tailoring the consensual regimen', are of intermediate value.

The two chapters on the effects of compliance levels and compliance distributions on the design and interpretation of clinical trials are illuminating and disturbing. Low levels of compliance could invalidate conclusions drawn after a standard analysis of the results of a drug trial, but the relevant data are not normally published which could enable an enquiring reader to examine this effect. Patients who 'drop out' of therapeutic trials should be followed up and described in some detail, since 'drop outs' could have a differential prognosis and therefore specious conclusions could be drawn concerning efficacy if based only on those patients who remain in the trial. The final chapter by Sackett usefully draws together the main recommendations for future research; so usefully in fact as to render redundant the corres- $\stackrel{\varnothing}{\varnothing}$ ponding parts of the individual chapters. However this duplication may be no bad thing, since each. chapter can stand alone and present $\vec{\overrightarrow{ }}$ a comprehensive coverage of a particular topic for the selective $\overline{\widehat{D}}$
reader.

It is also worth commenting upon. $\omega$ an unusual feature of this book. $\omega$ Appendix I includes an annotated $\vec{P}$ bibliography, in which papers are briefly described, and then ratedJ according to adequacy of design, sampling, illness specification, des- $\mathcal{D}$ cription of therapeutic regimen, definition of compliance and com $-\frac{\mathbb{D}}{3}$ pliance measures. Most of these papers have been referred to in the text. Thus one can determine not just the quantity but also the qualfy of the work and in a particular are. Furthermore tables are providefdo which enable one to determines 'where any particular article or group of articles stand with respect to the whole bibliography.' ThisD feature is quite useful and might hopefully provide a precedent foro other books to follow. However a note on the inter-rater reliability of the ratings would enhance the value of this procedure.

Generally speaking, this is and extremely useful book. There is a' refreshing emphasis on methodo 3 logical rigour, and its value in suggesting important new research topics is immense. Ethical issues are discussed intelligently, albeit briefly? Despite the foregoing, however, have some reservations about this book. First, some very importantr work in the area receives but brief mention, in particular the work of Ley $^{2}$ and his colleagues from Liverpool University, and the be- $\sigma$ havioural methods of Fordyce, Fowler and their colleagues at the्? Washington School of Medicine. Some potentially useful methods of ${ }^{\text {? }}$ increasing compliance are not dis- $\square$ cussed, for example, the use of returnable deposits, the amounf returned to the patient being prot而 portional to the degree of compli- $\frac{0}{0}$ 
ance. Second, the quality of the editing is poor: the subject index is inadequate (it does not include, for example, the crucial word 'placebo'); there is no name index; and, as mentioned previously the quality of the papers is variable. Third, the high standards of methodological sophistication demanded by the contributors are not always evident in the contributions themselves. For example, on p 36 Haynes refers to a one-tailed $t$ test, the results of which are said to favour the conclusion that studies demonstrating no relationship between a patient's knowledge of his disease and compliance are of greater methodological soundness than those studies which found a positive relationship. Haynes not only failed to report the $t$ value, and the associated level of probability, but also his use of a one-tailed $t$ test was inappropriate. A re-analysis of the data, using a more appropriate test (the Mann-Whitney $U$ test) reveals that the differences in methodological soundness are not in fact significant $(U=12, \quad P=>0.10)$. The failure to quote the inter-rater reliability of the qualitative ratings in Appendix I has already been noted. Finally, the book is very expensive: $f_{\mathrm{I}} \mathrm{z}$ for less than 200 pages of text is somewhat excessive, even if one takes into account the useful appendices. In short, the topics covered in this book are of exceptional importance, and the areas of research discussed could have profound implications for clinical practice and research. However, some of the important issues raised deserve better treatment, and I would like to have seen more selective and more careful editing. The book should be on the shelves of medical school libraries but individuals who buy it may subsequently query the wisdom and worth of their purchase.

DAVID F PECK

\section{References}

'Sand, P L, Fordyce, W E, and Fowler, $\mathbf{R} S$, Fluid intake behaviour in patients with spinal cord injury: Prediction and modification. Archives of Physical Medicine and Rehabilitation, 1973, 54, 254-262.

${ }^{2}$ Ley, P, Bradshaw, P W, Eaves, D, and Walker, CM, A method for increasing patients' recall of information presented by doctors. Psychological Medicine, 1973, 3, 217-220.

\section{The Medical Risks of Life}

Stephen Lock and Tony Smith

(Pp 328; 95p)

Penguin Books Ltd, Harmondsworth, Middlesex, England, 1976.

How ceaselessly we are reminded of the medical risks of life but in a book of that title more and better coordinated information is presented to the intelligent layman.

The joint authors, Dr Stephen Lock and Dr Tony Smith, begin at the beginning with a discussion in chapter I of what they call 'life patterns'. These include such factors as illegitimacy, separation at an early age - by death, divorce, or other means - and battering. Other life patterns with which we are all endowed are our own body rhythms (the body's time clock dubbing us owls or larks), our reactions to stress and to psychosomatic illness. These are broken down and analysed for our better understanding, and upon the discussion in the whole of this first chapter we may hang our medical progress through life.

As well as chapters dealing with diet and disease and its corollorary food poisoning, we are taught in others how to avoid diseases which may attack us as travellers, as pet lovers, as consumers of alcohol and of tobacco. On the positive side we are told how much exercise and sport is good for us at different ages, the hazards and benefits too of various occupations, and the dangers in our environment from not only what most of us regard as pollution but from other pollutants such as noise and even latitude, which is now being studied as a possible factor in the picture of multiple sclerosis.

Finally what are the prospects for a healthy life for our children? These are discussed in the context of the preceding chapters but certain specific topics are mentioned: prematurity and congenital abnormalities, and most importantly the effects on children of their mothers' physical and mental health, including the quality of the mothering given to the child.

And so we come to death: those illnesses characteristic of the different ages of man are summarized in such a way that the careful reader will recall the steps by which he can avoid each as far as is in his power as outlined in the earlier chapters.

The book is written in a clear, crisp and interesting style without condescension and without jargon or $\vec{\circ}$ a plethora of technical terms. There is a useful index, and a neat conclusion: $\operatorname{man}$ is a resilient creature and can survive much but also he can help himself to live to a good age in good health by digesting the facts set out by Dr Lock and Dr Smith and avoiding at least some of the medical risks of life.

GUNILLA LIDDLE 